\title{
СЕМАНТИЧЕСКОЕ ПОЛЕ Й. ТРИРА С ТОЧКИ ЗРЕНИЯ ФИЛОСОФСКОЙ ТЕОРИИ ФРЕЙМОВ
}

\section{THE SEMANTIC FIELD OF J. TRIER FROM THE VIEWPOINT OF THE PHILOSOPHICAL THEORY OF FRAMES}

\section{Menshchikov}

Summary: In this paper, a conceptual substantiation of frame problems is given, an attempt is made to identify the translation of the theory of the conceptual field of J. Trier into the philosophical theory of frames. The author considers the terms "frame" and "frame analysis" in the context of cognitive philosophy, compares the points of view on the understanding of these terms between linguistics and philosophy, and tries to combine these two theories into one.

Keywords: frame, frame theory, frame analysis, frame object, frame action, conceptual field, lexical field, semantic field.
$\mathrm{H}$ ачиная со второй половины XX века всё больше дисциплин размывают свои границы. Исходом этого появляются всё больше междисциплинарных связей, следствием чего стало явление перехода специальных методов и терминов из одной дисциплинарной области в другую с приобретением совершенно иного значения. В связи с этим стали появляться термины, не имеющие четкого определения и описывающие различные предметы изучения.

Одним из таких терминов является «фрейм». Сама теория, носящая название «теория фреймов» ведет своё начало от работ американских учёных Г. Бейтса, И. Гофмана, М. Минского. Это не полноценная теоретическая концепция, а совокупность различных концепций, развивающаяся в рамках социальных, психологических, когнитивных, лингвистических и кибернетических наук. Эти концепции организованы вокруг проблемы контекстуализации события действия. Сам термин «фрейм» является олицетворением контекста.

В данной работе за основу берётся модель представления фреймов, которую разработал Марвин Минский. Отметим, что фрейм состоит из терминала (определённого значения, которое можно записать в этот терминал) и маркера (определяющего, какое значение может быть записано в терминал). Набор маркера и терминала будем называть слотом или ячейкой.

Одним из таких терминов является «фрейм». Сама теория, носящая название «теория фреймов» ведет своё

\author{
Меньщиков Данил Игоревич \\ Аспирант, Российский университет транспорта (МИИТ) \\ menshchikov.danil@mail.ru
}

Аннотация: В данной работе даётся концептуальное обоснование проблем фреймов, делается попытка выявить перевести теорию понятийного поля Й. Трира в философскую теорию фреймов. Автор рассматривают термины «фрейм» и «фрейм-анализ» в контексте когнитивной философии, сравнивают точки зрения на понимание этих терминов между лингвистикой и философией и пытается объединить две эти теории в одну.

Ключевые слова: фрейм, теория фреймов, фрейм-анализ, фрейм-объект, фрейм-действие, понятийное поле, лексическое поле, семантическое поле.

начало от работ американских учёных Г. Бейтса, И. Гофмана, М. Минского. Это не полноценная теоретическая концепция, а совокупность различных концепций, развивающаяся в рамках социальных, психологических, когнитивных, лингвистических и кибернетических наук. Эти концепции организованы вокруг проблемы контекстуализации события действия. Сам термин «фрейм» является олицетворением контекста.

Фреймом будем называть единицу знания. Возьмём за основу, что существует два вида фрейма: фреймобъект и фрейм-действия. Фрейм-объект описывает знание о предмете, например, цвет или птица (иными словами, описывает существительные части речи). Фрейм-действие, аналогично, описывает знание о действии, в том числе и о принадлежности чего-то к чемуто, например, фраза «желтая птица» а теории фреймов будет описана следующим видом: «птица имеет жёлтый цвет».

Фрейм - это комплексный пакет знаний, хранимых на каком-либо носители (будь то компьютер или мозг человека). Фрейм описывает события и понятия. Каждый фрейм содержит отделения - слоты, в которых собраны атрибуты (характеристики) и соответствующие им значения. Например, фрейм определённого конкретного животного будет иметь слоты, где указаны вид животного, пол, ареал обитания и т. д., а также пустые слоты, которые можно заполнять новыми элементами знаний. Фреймы - это многослойная структура, нужная для отображения картины реальности, будь то чувственная ре- 
альность или лингвистическая, или любая другая. Возьмём эти определения за основу и попробуем привести каждую из вышеперечисленных областей знания к этой модели.

С конца 1970-х годов теорию фреймов начали развивать огромное число исследователей из огромного множества специальных научных областей. Предметом исследования при этом становились абсолютно несопоставимые явления - взаимоотношения индивидов в обществе, коммуникация в животном мире, психические процессы у человека, языковые явления, научная деятельность и т. д. [1, стр. 14].

Абсолютно каждый исследователь теории фреймов вносил свой вклад в понимание проблемы фреймов исходя из сферы интересов и цели своего исследования. Это привело к различию во взглядах на терминологический аппарат и его смысловое наполнение, что, в свою очередь, привело к появлению разных интерпретаций этого понятия, а в дальнейшем - различных вариантов фрейм-анализа [2, стр. 29]. В настоящее время данная теория также разрабатывается во многих областях науки, будь то лингвистика, социология, психология, педагогика и т.д. Исследователи, представляющие разные научные дисциплины, обогащают понятие фрейма своим содержанием и адаптируют его применительно к своему научному материалу [3, стр. 140].

Историю разработки теории фреймов можно разделить на следующие этапы:

- В работе Марвина Минского была представлена математическая модель описания фреймов и их систем, на основе которых была представлена графическая модель представления как единичного фрейма, так и системы фреймов, описывающих объект.

- В работе Р. Шенка и Р. Абельсона была представлена модель графического представления фреймсценариев являющимися представлением действий и явлений (скриптов) в конкретной системе фреймов.

- В работе Йоста Трира и Лео Вайсгербера бы введен термин «отношение», являющийся, в конкретном случае, представлением обобщения или сходства для двух понятий, описанными в конкретной системе фреймов.

- В работе Грегори Бейтсона была развита модель Й. Триста и термин «отношение», являющийся в общем случае представлением любого отношения между двумя конкретными объектами, а также был описан механизм коррекции ошибок выбора альтернатив действия и механизм переходов между уровнями обобщения (абстракция) объектов конкретной системы фреймов.

- В работе Ирвинга Гофмана был описан меха- низм обобщения сценариев конкретной фреймсистемы и механизм построения переходов между уровнями обобщения (абстракция) этих сценариев конкретной системы фреймов.

- В работе Ч. Филлмора была представлена модель фрейма явления, являющимся набором всех фреймов участников конкретного явления, а также всех фрейм-сцен сценариев взаимодействия между участниками этого конкретного явления.

Вообще говоря, попытки вести исследования в направлении понимания фреймов (хоть тогда определения, описывающие такое явление, как фреймовый анализ, звучали по-другому) начались еще в XIX веке при построении теорий поля лингвистами. Автор не считает целесообразным углубляться в историю этого вопроса, для исследования интересна теория семантического поля, разработанная в 30-е годы XX века Й. Триром и Л. Вайсгербером. Суть этой теории в том, что, по мнению исследователей, в первую очередь Й. Трира, слово имеет смысл лишь потому, что слова, смежные с ним, также имеют смысл. По мнению Й. Трира (а после и Л. Вайсгербера, продолжившим развивать это концепцию) «вне поля слово вообще не может иметь значения» [4, стр. 11], [5, стр. 5]. Язык, по мнению Й. Трир, с позиции синхронного анализа - есть стабильная замкнутая система, в которой «все получает смысл только из целого» [6, стр. 106]. Рассмотрим основные положения этой концепции:

1. в основе членения словарного состава лежит «понятийным полям» (логический подход), которому соответствуют «лексические поля», образующее лексические единицы;

2. действительность членится понятийными полями абсолютно и без остатка; как следствие - полный параллелизм, изоморфизм языка и мышления;

3. понятийные поля являются замкнутыми и отграниченными друг от друга;

4. язык и действительность находятся в тесной взаимосвязи, что обусловливает понимание внутренней формы языка как выражения мироощущения его носителей, которое изменяется во времени;

5. слово не существует в языке изолированно от других слов, и ни одно слово не стоит отдельно в сознании говорящего и слушающего.

Проще говоря, адекватное толкование значения термина зависит от лексических единиц, которые входят в одно и то же семантическое поле данного языка, и от его семантических отношений с другими членами этого поля. При исследовании языка выделяются изолированные семантические поля (области) лексики на основе различных отношений входящих в них языковых единиц (родовидные, синонимические, «часть-целое» и так далее). Так, например, в русском и немецком языках, содержание и объем значений слов, входящих в семантическое поле обозначений интервалов в пределах 
суток, отличается. То есть, когда носитель немецкого языка употребил бы слово «vormittag» (предполуденное время), входящее в семантическое поле вместе с лексическими единицами «утро», «послеполуденное время», «вечер» и «ночь», носитель русского языка употребит слово «утро». Иными словами, для чёткого определения границ слов «утро» и «вечер», необходимо точно знать существующий как самостоятельные сущности отрезки времени суток в данном конкретном языке, или, другими словами, знать объём и содержание всего семантического поля. Одни семантические поля могут как содержать одинаковые языковые единицы с множеством значений, так и пересекаться, и быть связанными с другими семантическими полями, что, в свою очередь, образует языковую систему. Позже, Л. Вайсгербер дополнил теорию добавив, что концептуальные системы, лежащих в основе конкретных языков - неповторимы. В структурной семантике и связанной с ней теории семантического поля отдельные концепты, а также значения обозначающих их лексических единиц, рассматриваются не как объективно существующие, внеязыковые феномены, а как создаваемые языком «духовные объекты», структурирующие действительность. Слово - это минимальная зависимая единица, которая существует только благодаря целому, т.е. лексическому полю. «Чтобы понять значение отдельного слова, - пишет Л. Вайсгербер, - надо представить все поле и найти в его структуре место этого компонента». Языковое поле образует как бы промежуточный мир между внешним миром и сознанием человека определенной языковой общности.

В своей работе Й. Трир также описал разработанный им экстралингвистический подход исследования семантических полей. По Й. Триру, язык является замкнутой самостоятельная система, которая определяет сущность в сознании в виде системы понятий, представляющая собой содержательную сторону языка и участвующая в его членении. В 1931 году Й. Трир ввел понятие «понятийное поле», называя его «непосредственным отражением действительности» [7, стр. 176] и содержащем в себе лингвистическое описание. Понятийное поле понимается, в первую очередь, как структура определенной понятийной сферы или круга понятий. В языке аналогом понятийного поля служит словесное (или лексическое) поле, которое самостоятельно или изолированно не существует вне словарного состава, а вычленяется из него лишь будучи соотнесённым с каким-либо понятийным полем [8, стр. 2], т. е. каждому полю в понятийной сфере в языке соответствует лексическое поле, которое состоит из совокупности отдельных фраз. Слова, констатирующие такие объединения, связанны или парадигматическими, или синтагматическими (синтаксическими) отношениями» [9, стр. 90]. Эти же слова, существующие в сознании человека по группам, образуют некую смысловую сферу.
Лексические поля очерчивают границы соответствующим пространствам понятийных поле, или, проще говоря, лексические поля покрывают соответствующие пространства понятийных полей. Состав лексического поля (самостоятельной единицу, занимающее промежуточное положение между системой языка в целом и отдельным словом) определяет принадлежность слов к понятийному полю (способность выражать определённый круг понятий). Поле - есть «совокупность слов, находящихся в свободных связях по линии их лексического значения в тот или иной период времени. Понятийное и словесное поля содержат компоненты, причем компоненты словесного поля полностью покрывают компоненты понятийного поля. Как уже было сказано, лексическое поле является самостоятельным потому, что отдельные слова не являются обособленными носителями значений. Поэтому человек в состоянии понимать отдельные слова только тогда, когда в его сознании присутствуют всё поле словесных знаков, иначе говоря, слово имеет значение только внутри целого поля и благодаря этому целому.

Возьмём в качестве атомарной (неделимой) единицей слово. Выше говорилось, что само по себе слово не имеет значение, значение оно приобретает только тогда, когда попадает в семантическое поле и становится лексической единицей. Лексической единицей же называется отношение между понятийным полем и лексическим полем.

Рассмотрим ряд слов: осина, береза, дуб. Гиперонимом (обобщением) этого ряда является слово «дерево, а каждое из слов ряда является гипонимом по отношению к слову «дерево». Данный ряд является множеством пород дерева. Проанализировав его, можно обнаружить в этих значениях общие для всех этих слов смысловые компоненты (семы) и специфические, присущие значению только данного слова. Семой для приведённого ряда является слово «дерево»: толкование каждого из этих слов невозможно без указания на то, что данный природный объект принадлежит к классу деревьев. Таким образом, нетрудно догадаться, что лексическим полем в данном семантическом поле будут являться слова: осина, береза, дуб, - а понятийном поле будет являться только слово «дерево». Соединив компоненты понятийного и лингвистического полей, получим три лексических единицы, являющиеся объектами отношения «принадлежит». В прошлом параграфе было сказано, что такие отношения называются фактами. Таким образом, факты звучат следующим образом: дуб принадлежит дереву, береза принадлежит дереву, осина принадлежит дереву.

Вернёмся к фреймам. Фрейм нашего семантического поля состоит из трёх уровней: на самом нижнем находятся фреймы слова (их 4, для слова «дерево» также не- 
обходим фрейм), дальше идут фреймы отношения «принадлежит» и на самом верхнем уровне находится фрейм семантическое поле.

Рассмотрим фразу «цветы растут на опушке». Для понимания этой фразы необходимо построить следующую систему фреймов: цветок является растением, опушка является краем леса, лес является множеством деревьев, деревья являются растениями, рост является существованием.

Таким образом видно, что понятийные поля Й. Трира в лингвистике являются аналогом теории фреймов в философии. Рассмотрим основные понятия теории Й. Трира и переведём их в язык теории фреймов:

1. Слово является атомарным фрейм-объектом;

2. Лексическое поле является набором фреймов «слово», по смыслу являющиеся гипонимом хотя бы одного фрейма слово из понятийного поля;
3. Понятийное поле является набором фреймов «слово», по смыслу являющиеся гиперонимом хотя бы одного фрейма слово из лексического поля;

4. Лексическая единица - это факт, являющийся фреймом отношение, включающий в себя терминал с названием отношения (в данном примере это отношение «принадлежит»), терминал, маркером которого является один из фреймов слово лексического поля и терминал, маркером которого является один из фрейма слово понятийного поля;

5. Семантическое поле является фреймом, включающий в себя динамический набор фреймов отношение (факты).

6. Таким образом, для теории семантического поля теория фреймов является, так сказать, дженериком (Generic), шаблоном, в который эта теория отлично вписывается.

\section{ЛИТЕРАТУРА}

1. Некрасов Сергей Иванович и Молчанова Наталья Сергеевна Значение теории фреймов в современной науке [Статья] // Научные ведомости Белгородского государственного университета. Серия: Философия. Социология. Право. - Белгород: ФГАОУВО «Белгородский государственный университет», 2009 г.. - 10 : Т. 16. - стр. 13-17.

2. Гусельникова Олеся Валентиновна Возможности фреймового анализа [Статья] // Мир науки, культуры, образования. - Горно-Алтайск: Редакция международного научного журнала Мир науки, культуры, образования, 2009 г.. - 5. - стр. 29-32.

3. Гусельникова Олеся Валентиновна Терминологический аппарат структуры фрейма [Статья] // Вестник Южно-Уральского государственного гуманитарнопедагогического университета. - Челябинск: [б.н.], 2010 г. - 9. - стр. 137-149.

4. Шафиков Сагит Гайлиевич Теория семантического поля и компонентной семантики его единицы [Книга]. - Уфа: Башкирский университет, 1999.

5. Трир Йост Der deutsche Wortschatz im Sinnbezirk des Verstandes. Die Geschichte eines Sprachlichen feldes, [Книга]. - Heidelberg: [6.н.], 1931.

6. Васильев Л.М. Теория семантических полей [Статья] // Вопросы языкознания. - 1971 г.. - 3. - стр. 105-113.

7. Караулов Юрий Николаевич Общая и русская идеография [Книга]. - Москва: Наука, 1976.

8. Жоламанова Е.И. Теория семантического поля: традиции и новации. - [б.м.]: Американский университет в Центральной Азии, 2009 г..

9. Щур Георгий Семенович Теория поля в лингвистике. - Москва: Наука, 1974 г. 